HKIBS/WPS/032-989

June, 99

\title{
Further Sufficient Conditions \\ for an Inverse Relationship \\ between Productivity and \\ Employment
}

\author{
Clement K. W. CHOW \\ Department of Marketing \& \\ Hong Kong Institute of Business Studies \\ Lingnan College \\ and \\ Kit Pong WONG \\ School of Economics and Finance \\ University of Hong Kong
}

Hong Kong Institute of Business Studies

Lingnan College

Tuen Mun

New Territories

Hong Kong

Tel: (852) 26168373

Fax: (852) 25724171 


\title{
Further Sufficient Conditions for an Inverse Relationship between Productivity and Employment
}

\author{
Clement K. W. CHOW \\ Department of Marketing \& \\ Hong Kong Institute of Business Studies \\ Lingnan College \\ Tuen Mun, Hong Kong \\ Telephone: (852) 26168370 \\ Fax: (852) 25724171 \\ E-mail:ckwchow@ln.edu.hk \\ and \\ Kit Pong WONG * \\ School of Economics and Finance \\ University of Hong Kong \\ Pokfulam Road, Hong Kong \\ Telephone: (852) 28591044 \\ Fax: (852) 25481152 \\ E-mail:kpwong@econ.hku.hk
}

* Please direct all correspondence to: Kit Pong WONG. 


\begin{abstract}
Extant empirical studies document that productivity gains due to technological progress often lead to reductions in employment. This paper rationalizes the stated empirical finding within the context of the theory of the competitive firm under price uncertainty. We show that technological progress affects employment adversely if the firm's coefficient of relative risk aversion is no less than unity and its production technology exhibits non-decreasing returns to scale. On the other hand, technological progress unambiguously increases output if the firm's preference is non-increasing absolute risk aversion.
\end{abstract}




\section{Further Sufficient Conditions for an Inverse Relationship between Productivity and Employment}

According to the microeconomic theory of the firm, the optimal input choice of a competitive firm is the one which equates the value of the marginal product to the price of the input (see, e.g., Varian, 1996, p. 322). An immediate implication is that the firm should increase its level of input, thereby its level of output, in response to productivity gains due to technological progress, ceteris paribus. Empirical evidence, however, shows quite the opposite: technological progress that improves labor productivity normally leads to a decrease, rather than an increase, in employment. For example, using data on the Finnish manufacturing sector, Pehkonen (1992) augments the employment-output equation with a variable which captures the effects of technological progress on employment. His results imply that technological progress on average reduces employment by 4 percent per annum. Frey and Vivarelli (1991), on the other hand, rely on data on the Italian telecommunications sector and document a correlation between technological change and the sharp fall in employment in the 1980s.

To rationalize the stated empirical consequence of technological progress on employment, Firoozi (1994) incorporates output price uncertainty and firm's attitude towards risk along the lines of Sandmo (1971) and Batra and Ullah (1974) into the analysis. His model features a competitive risk-averse firm which employs labor as the sole input for the production of a single good with an unknown price. Technological progress is specified by a multiplicative productivity index to the firm's production function. The objective of Firoozi (1994) is to characterize sufficient conditions under 
which the firm will reduce employment and raise output in the face of technological progress that improves labor productivity. As will be shown shortly, the "sufficient conditions" derived by Firoozi (1994) are not sufficient conditions per se, but rather a tautology.

The purpose of this paper is thus to complete the incomplete analysis of Firoozi (1994). We show that coefficients of relative risk aversion of Arrow (1965) and Pratt (1964) and returns to scale of production technologies are important determinants of the relationship between employment and output resulting from technological progress. Specifically, we show that technological progress affects employment adversely if the firm's coefficient of relative risk aversion is no less than unity and its production technology exhibits non-decreasing returns to scale. On the other hand, technological progress unambiguously increases output if the firm's preference is nonincreasing absolute risk aversion. In other words, sufficient conditions under which an inverse relationship between employment and output due to technological progress prevails are that the firm's preference satisfies non-increasing absolute risk aversion, its coefficient of relative risk aversion is no less than one, and its production technology exhibits non-decreasing returns to scale.

The rest of the paper is organized as follows. Section I describes the model of Firoozi (1994) in which a competitive risk-averse firm faces output price uncertainty and technological progress that improves labor productivity. Section II points out that the "sufficient conditions" provided by Firoozi (1994) for an adverse employment consequence of technological progress are de facto a tautology. Further sufficient conditions are derived and contrasted with the extant empirical findings. Section III draws some conclusions. 


\section{THE MODEL}

In the model developed by Firoozi (1994), a competitive risk-averse firm employs labor, $L$, at a known wage rate, $w$, as the sole input for the production of a single good, $X$. The production technology of the firm can be described by a function, $X=A F(L)$, where $A$ is a positive constant representing a multiplicative productivity index, and $F$ is an increasing and twice continuously differentiable function. When the firm makes its production decision, the output price, $P$, is uncertain to the firm. $P$ is a non-negative random variable with known probability distribution function. This set up is along the lines of Sandmo (1971) and Batra and Ullah (1974).

Under output price uncertainty, the firm's profit is stochastic and is given by

$$
\pi=P X-w L=P A F(L)-w L
$$

The firm possesses a von Neumann-Morgenstern utility function, $U$, defined over its profit, with $U^{\prime}>0$ and $U^{\prime \prime}<0$ (i.e., the firm is risk averse). The firm chooses its labor employment, $L$, so as to maximize its expected utility, $\mathrm{E}[U(\pi)]$, where $\pi$ is given in equation (1). The first-order condition for a maximum is

$$
\mathrm{E}\left[U^{\prime} h\right]=0,
$$

where $h=P A F_{L}-w$. The second-order" condition for a maximum is

$$
\mathrm{E}\left[U^{\prime} P\right] A F_{L L}+\mathrm{E}\left[U^{\prime \prime} h^{2}\right]<0
$$

which is assumed to hold. A sufficient (but not necessary) condition to guarantee the second-order condition is that $F_{L L} \leq 0$. 


\section{THE EFFECTS OF TECHNOLOGICAL PROGRESS ON EMPLOYMENT AND OUTPUT}

Following Firoozi (1994), we model technological progress that improves labor productivity by an increase in the multiplicative productivity index, $A$. Totally differentiating equation (2) with respect to $A$ yields

$$
\frac{\mathrm{d} L}{\mathrm{~d} A}=-\frac{\mathrm{E}\left[U^{\prime} P\right] F_{L}+\mathrm{E}\left[U^{\prime \prime} P h\right] F}{\mathrm{E}\left[U^{\prime} P\right] A F_{L L}+\mathrm{E}\left[U^{\prime \prime} h^{2}\right]} .
$$

From the second-order condition, (3), the denominator in the right-hand side of equation (4) is negative. Thus, the sign of $\mathrm{d} L / \mathrm{d} A$ is the same as the sign of the numerator in the right-hand side of equation (4).

The term, $\mathrm{E}\left[U^{\prime} P\right] F_{L}$, is unambiguously positive. Using the compensation method proposed by Davis (1989), this term captures the substitution effect which is the change in the optimal labor employment due to technological progress, holding the firm's expected utility constant. The substitution effect has to be positive because technological progress improves labor productivity which, in turn, induces the firm to employ more labor, as suggested by the microeconomic theory of the firm.

The term, $\mathrm{E}\left[U^{\prime \prime} P h\right] F$, captures the income effect which arises because technological progress increases the firm's profit by $P F$ in all possible states, contributing to higher level and randomness of the firm's profit. Note that

$$
P F=\frac{F}{A F_{L}}(h+w) .
$$

Using the above equation, we have

$$
\mathrm{E}\left[U^{\prime \prime} P h\right] F=\mathrm{E}\left[U^{\prime \prime} h^{2}\right] \frac{F}{A F_{L}}+\mathrm{E}\left[U^{\prime \prime} h\right] \frac{w F}{A F_{L}} .
$$

Thus, the income effect can be further decomposed into two components. The first component, $\mathrm{E}\left[U^{\prime \prime} h^{2}\right] F / A F_{L}$, represents the income effect arising from the increased 
randomness of the firm's profit due to technological progress. It is unambiguously negative under risk aversion (i.e., $U^{\prime \prime}<0$ ). The second component, $\mathrm{E}\left[U^{\prime \prime} h\right] w F / A F_{L}$, represents the income effect that comes from the increased level of the firm's profit due to technological progress. In general, its sign is indeterminate.

Firoozi (1994) restricts his attention to the case where $U$ exhibits constant absolute risk aversion (CARA). According to Arrow (1965) and Pratt (1964), $U$ exhibits CARA if $-U^{\prime \prime}(\pi) / U^{\prime}(\pi)=r$ for all $\pi$, where $r$ is a positive constant. In this case, we have

$$
\mathrm{E}\left[U^{\prime \prime} h\right]=-r \mathrm{E}\left[U^{\prime} h\right]=0
$$

where the first equality follows from CARA and the second equality follows from the first order condition, (2). This is quite intuitive because the component of the income effect due entirely to changes in the level of the firm's profit should have no effect on the firm's decision if the firm's preference is CARA. Thus, the income effect is unambiguously negative and works against the substitution effect, resulting in an a priori indeterminate employment consequence of technological progress.

Under CARA, we have shown that $\mathrm{E}\left[U^{\prime \prime} P h\right]=-r \mathrm{E}\left[U^{\prime} P h\right]<0$. In other words, case (b) in Firoozi (1994, p. 304), i.e., $\mathrm{E}\left[U^{\prime} P h\right] \leq 0$, is totally irrelevant. To find sufficient conditions that ensure $\mathrm{d} L / \mathrm{d} A<0$, Firoozi (1994) defines the following variable:

$$
v=\frac{\mathrm{E}\left[U^{\prime} P\right] F_{L}}{\mathrm{E}\left[U^{\prime} P \dot{h}\right] F},
$$

which has already been shown to be positive. Firoozi (1994) claims that a "sufficient condition" for $\mathrm{d} L / \mathrm{d} A<0$ is that $r>v$. However, $r>v$ is simply a restatement that the numerator in the right-hand side of equation (4) is negative under CARA, thereby $\mathrm{d} L / \mathrm{d} A<0$. Thus, $r>v$ is not a sufficient condition for $\mathrm{d} L / \mathrm{d} A<0$ per se, but rather is a tautology. 
As will be shown shortly, the notion of relative risk aversion developed by Arrow (1965) and Pratt (1964) plays a pivotal role in determining the relationship between employment and output. According to Arrow (1965) and Pratt (1964), the coefficient of relative risk aversion is defined as $R(\pi)=-\pi U^{\prime \prime}(\pi) / U^{\prime}(\pi)$ for any given $\pi$. Let us write the numerator in the right-hand side of equation (4) as

$$
\mathrm{E}\left[U^{\prime} P\right] F_{L}+\mathrm{E}\left[U^{\prime \prime} P h\right] F+\mathrm{E}\left[U^{\prime \prime} P \pi\right] F_{L}-\mathrm{E}\left[U^{\prime \prime} P \pi\right] F_{L}
$$

where $\pi$ is defined in equation (1). Using the coefficient of relative risk aversion, the above expression can be rewritten as

$$
-\mathrm{E}\left[U^{\prime} P(R-1)\right] F_{L}-\mathrm{E}\left[U^{\prime \prime} P\right] w\left(F-F_{L} L\right) .
$$

Thus, $\mathrm{d} L / \mathrm{d} A<0$ if expression (5) is negative. Note that the first term in expression (5) is negative if $R \geq 1$ and the second term is negative if $F_{L} \geq F / L$.

If the function, $F$, is homogenous of degree $\alpha$, then $F(L)=a L^{\alpha}$ (see Silberberg, 1990, p. 103), where $a$ is a positive constant. The firm's production technology is said to exhibit increasing, constant, or decreasing returns to scale if $\alpha$ is greater than, equal to, or less than unity, respectively. Hence, sufficient conditions for technological progress to have a perverse effect on employment are that the firm's coefficient of relative risk aversion is no less than one and its production technology exhibits nondecreasing returns to scale (i.e., $\alpha \geq 1$ ).

According to the empirical study of Friend and Blume (1975), coefficients of relative risk aversion are typically in excess of one and tend to be at least two. It follows that the sufficient conditions boil down to returns to scale of production technologies only: If the firm's production technology exhibits non-decreasing returns to scale, then the employment consequence of technological progress will be negative. This yields a new testable implication. Indeed, in the empirical examination of the 
performance of the employment-output equation in Finland, Pehkonen (1992) finds constant returns to scale and a 4 percent reduction in employment per annum due to technological progress. The negative employment consequence of technological change in Italy's telecommunications sector documented by Frey and Vivarelli (1991) is also consistent with non-decreasing returns to scale.

Finally, we want to show an inverse relationship between employment and output in response to technological progress. To this end, totally differentiating the production function, $X=A F(L)$, with respect to $A$ yields

$$
\begin{aligned}
\frac{\mathrm{d} X}{\mathrm{~d} A} & =F+A F_{L} \frac{\mathrm{d} L}{\mathrm{~d} A} \\
& =-\frac{\mathrm{E}\left[U^{\prime \prime} h\right] w F-\mathrm{E}\left[U^{\prime} P\right] A\left[F F_{L L}-F_{L}^{2}\right]}{\mathrm{E}\left[U^{\prime} P\right] A F_{L L}+\mathrm{E}\left[U^{\prime \prime} h^{2}\right]}
\end{aligned}
$$

where the second equality follows from equation (4). Hence, we have $\mathrm{d} X / \mathrm{d} A>0$ should the numerator in the right-hand side of equation (6) be positive.

If the function, $F$, is homogenous of degree $\alpha$, then $F F_{L L}-F_{L}^{2}=-F_{L}^{2} / \alpha<0$. Hence, to show $\mathrm{d} X / \mathrm{d} A>0$, it suffices to show that $\mathrm{E}\left[U^{\prime \prime} h\right] \geq 0$. First, if $U$ exhibits CARA, then it follows from the first-order condition, (2), that $\mathrm{E}\left[U^{\prime \prime} h\right]=-r \mathrm{E}\left[U^{\prime} h\right]=$ 0 . Second, if $U$ exhibits decreasing absolute risk aversion (DARA), then we have

$$
-\frac{U^{\prime \prime}(P A F-w L)}{U^{\prime}(P A F-w L)}<(>)-\frac{U^{\prime \prime}(\hat{P} A F-w L)}{U^{\prime}(\hat{P} A F-w L)} \text { for } P>(<) \hat{P}=\frac{w}{A F_{L}} .
$$

Multiplying $-U^{\prime} h$ to both sides of the above inequality and taking expectations with respect to $P$ yields

$$
\mathrm{E}\left[U^{\prime \prime} h\right]>\frac{U^{\prime \prime}(\hat{P} A F-w L)}{U^{\prime}(\hat{P} A F-w L)} \mathrm{E}\left[U^{\prime} h\right]=0
$$

where the equality follows from the first-order condition, (2). Hence, if the production function is homogenous and the firm's preference is either CARA or DARA, we have $\mathrm{d} X / \mathrm{d} A>0$. 
To summarize, we find that the sufficient conditions under which an inverse relationship between employment and output due to technological progress prevails are that (i) the firm's preference is non-increasing absolute risk aversion, (ii) the firm's coefficient of relative risk aversion is no less than one, and (iii) the firm's production technology exhibits non-decreasing returns to scale.

\section{CONCLUSIONS}

Extant empirical studies document that productivity gains due to technological progress often lead to reductions in employment. At first sight the microeconomic theory of the firm seems unable to reconcile the stated empirical finding. This paper, however, has shown that the negative employment consequence of technological progress can be rationalized within the context of the theory of the competitive firm under price uncertainty if the firm's coefficient of relative risk aversion is no less than unity and its production technology exhibits non-decreasing returns to scale. Furthermore, technological progress unambiguously increases output if the firm's preference is non-increasing absolute risk aversion.

As shown in Eeckhoudt and Gollier (1995), the commonly used utility functions such as the logarithmic utility function and the negative exponential utility function satisfy non-increasing absolute risk aversion and coefficients of relative risk aversion above unity. Thus, under those utility functions, an inverse relationship between employment and output prevails if the firm's production technology exhibits nondecreasing returns to scale. This empirical implication finds indirect support from Pehkonen (1992) and Frey and Vivarelli (1991), though a more direct test is warranted. 


\section{REFERENCES}

Arrow, Kenneth J. 1965. Aspects of the Theory of Risk-Bearing. Helsinki: Yrjo Jahnsson Saatio.

Batra, Raveendra N., and Aman Ullah. 1974. "Competitive Firm and the Theory of Input Demand under Price Uncertainty." Journal of Political Economy 82: $537-548$.

Davis, George K. 1989. "Income and Substitution Effects for Mean-Preserving Spreads." International Economic Review, 30: 131-136.

Eeckhoudt, Louis, and Christian Gollier. 1995. Risk: Evaluation, Management and Sharing. New York: Harvester Wheatsheaf.

Firoozi, Fathali. 1994. "Sufficient Conditions for an Inverse Relationship between Productivity and Employment." Quarterly Review of Economics and Finance 34: 301-307.

Frey, Marco, and Marco Vivarelli. 1991. "New Technology and Employment in Italian Telecommunications." Technovation, 11: 303-313.

Friend, Irwin, and Marshall E. Blume. 1975. "The Demand for Risky Assets." American Economic Review 65: 900-922.

Pehkonen, Jaakko. 1992. "Survey Expectations and Stochastic Trends in Modelling the Employment-Output Equation." Oxford Bulletin of Economics and Statistics, 54: 579-589.

Pratt, John W. 1964. "Risk Aversion in the Small and in the Large." Econometrica, 32: $122-136$.

Sandmo, Agnar. 1971. "On the Theory of the Competitive Firm under Price Uncertainty." American Economic Review 61: 65-73.

Silberberg, Eugene. 1990. The Structure of Economics: A Mathematical Analysis. 2nd ed. New York: McGraw-Hill.

Varian, Hal R. 1996. Intermediate Microeconomics: A Modern Approach. 4th ed. New York: W.W. Norton \& Company. 